\title{
The porosity in a fluidized bed heat transfer model
}

\author{
G. VISSER and M. VALK \\ Department of Thermal Engineering, University of Twente, P.O. Box 217, 7500 AE Enschede,
}

The Netherlands

(Received 30 December 1991 and in final form 27 March 1992)

\begin{abstract}
A mathematical model of heat transfer between a fluidized bed and an immersed surface and a model of gas flow and porosity, both recently published, were combined and further modified in the area of low velocities where the particle convective component of heat transfer is low or neglectable. Experimental work consisted of measurements of both porosity and heat transfer in a cold fluidized bed of sand. Five samples of sand, each having a narrow size range, were investigated; the mean particle diameter varied from 0.43 to $1.55 \mathrm{~mm}$. Also two mixtures of these samples, which yielded a wide particle size distribution, were tested. Experimental results showed good agreement with model predictions, for both porosity and heat transfer.
\end{abstract}

\section{INTRODUCTION}

AN IMPORTANT property of fluidized beds applied in various chemical and physical processes is the high rate of heat transfer between the bed and the immersed surfaces. However, an accurate prediction of the heat transfer coefficient, necessary for a reliable design of fluidized bed equipment, is still difficult to obtain. During the past forty years, many models and correlations have been developed, but generally these are reliable in only a restricted area of operation. This is caused by the complexity of fluidized bed heat transfer and hydrodynamics with their many variables.

Heat transfer from a fluidized bed to a surface (or vice versa) consists of a particle convective, a gas convective and a radiative part. In most practical situations, a combination of two or three parts has to be considered, while previous literature only treats one part : either small particles whose primary heat transfer process is by particle convection, or large particles for which gas convective heat transfer is the most important mechanism.

Recently, Borodulya et al. [1] developed their twozone model, based partly on theory and partly on experiments. This model provides a reliable prediction of the heat transfer coefficient over a wide range of pressures, temperatures and particle diameters. Dependence on fluidizing velocity, however, is not correctly taken into account, because the model neglects the decrease of particle convective heat transfer at velocities less than $U_{\text {opt }}$ and the total absence of particle convection when the gas velocity is less than $U_{\mathrm{m} r}$. At these velocities the bed is not fluidized, which implies that no replenishment of particles at the heat transfer surface takes place. Thus there is no temperature difference between bed and surface which is elementary for particle convection. Gas convective heat transfer is not affected by particle motion.
An important hydrodynamic variable in the model is the porosity or voidage of the bed material, because this variable determines the amount of gas convective relative to particle convective heat transfer. The original relations proposed in the model [2] to predict the porosity are partly based on the two-phase theory of fluidization, whose reliability in the case of large particles is not proven. For an accurate prediction of porosity a complete analysis of gas flow, solids motion and bed geometry is needed. Glicksman et al. [3] developed a model which applies to beds both with and without internals such as cooling pipe arrays.

In this investigation the porosity model of Glicksman and the heat transfer model of Borodulya were combined, and a modification was made to improve model predictions in the area of low velocities (from 0 to $U_{\text {opt }}$ ).

\section{THEORY}

Borodulya et al. [2] model the heat transfer coefficient as an effective conductivity divided by an effective conduction path length. The result is fitted with their own experimental results and with literature data. Their correlation for ambient temperature and pressure is

$$
N u=7.2(1-\varepsilon)^{2 / 3}+0.044 \operatorname{Re} \operatorname{Pr}(1-\varepsilon)^{2 / 3} / \varepsilon .
$$

The first term represents the particle convective part, the second term the gas convective part of hcat transfer. Later, Borodulya et al. [1] modified this formula so that it correctly describes the influence of particle diameter on heat transfer for small particles. This is done by introducing the Archimedes number into equation (1). After fitting with experimental results from the literature, the following formula results :

$N u=2.62 A r^{0.1}(1-\varepsilon)^{2 / 3}+0.033 \operatorname{Re} \operatorname{Pr}(1-\varepsilon)^{2 / 3} / \varepsilon$. 


\section{NOMENCLATURE}

\begin{tabular}{|c|c|c|c|}
\hline$A r$ & $\begin{array}{l}\text { Archimedes number, } g d_{\mathrm{p}}^{3} \rho_{\mathrm{r}}\left(\rho_{\mathrm{p}}-\rho_{\mathrm{r}}\right) / \mu_{\mathrm{r}}^{2} \\
\text { specific heat at constant pressure }\end{array}$ & $z$ & axial coordinate $[\mathrm{m}]$. \\
\hline & {$\left[\mathrm{J} \mathrm{kg}^{-1} \mathrm{~K}^{-1}\right]$} & \multicolumn{2}{|c|}{ Greek symbols } \\
\hline$d$ & diameter $[\mathrm{m}]$ & $\delta$ & bubble fraction \\
\hline Fr & modified Froude number, $\left(U-U_{\mathrm{mr}}\right)^{2} / g H_{\mathrm{mr}}$ & $\boldsymbol{E}$ & porosity \\
\hline$g$ & gravitational acceleration $\left[\mathrm{m} \mathrm{s}^{-2}\right]$ & $\lambda$ & thermal conductivity $\left[\mathrm{W} \mathrm{m}^{-1} \mathrm{~K}^{-1}\right]$ \\
\hline$H$ & bed height $[\mathrm{m}]$ & $\mu$ & dynamic viscosity $\left[\mathrm{kg} \mathrm{m}^{-1} \mathrm{~s}^{-1}\right]$ \\
\hline$h$ & $\begin{array}{l}\text { external heat transfer coefficient } \\
{\left[\mathrm{W} \mathrm{m}^{-2} \mathrm{~K}^{-1}\right]}\end{array}$ & $\rho$ & density $\left[\mathrm{kg} \mathrm{m}^{-3}\right]$. \\
\hline$K$ & through-flow coefficient & & \\
\hline$N_{0}$ & number of orifices per $\mathrm{m}^{2}$ in a distributor & \multirow{2}{*}{\multicolumn{2}{|c|}{ Subscripts }} \\
\hline & plate & & \\
\hline$N u$ & Nusselt number, $h d_{\mathrm{p}} / \lambda_{\mathrm{r}}$ & $\mathrm{b}$ & bubble \\
\hline $\operatorname{Pr}$ & Prandtl number, $c_{\mathrm{r}} \mu_{\mathrm{r}} / \lambda_{\mathrm{r}}$ & f & gas \\
\hline$p$ & pressure $\left[\mathrm{N} \mathrm{m}^{-2}\right]$ & $i$ & $i$ th fraction \\
\hline$\Delta p$ & pressure differcnce $\left[\mathrm{N} \mathrm{m}^{-2}\right]$ & $\mathrm{mf}$ & minimum fluidization \\
\hline $\operatorname{Re}$ & Reynolds number, $U d_{\mathrm{p}} \rho_{\mathrm{f}} / \mu_{\mathrm{f}}$ & opt & optimum \\
\hline$U$ & superficial gas velocity $\left[\mathrm{m} \mathrm{s}^{-1}\right]$ & 0 & entrance \\
\hline$w$ & weight fraction & $\mathrm{p}$ & particles. \\
\hline
\end{tabular}

Formula (2) can be used when $0.1<d_{\mathrm{p}}<4.0 \mathrm{~mm}$. Other correlations are developed for higher temperatures and pressures [1].

One objection against these formulas is that the particle convective term (thus the first term in both formulas) has a fixed minimum value when gas velocity drops down to zero (because of the minimum value for $\varepsilon$ ). In practice, however, particle convective heat transfer can be neglected at velocities below $U_{\mathrm{mr}}$ and is only small when $U_{\mathrm{mf}}<U<U_{\mathrm{opt}}$ because particles at the surface are stationary or seldom refreshed. To adapt the model to this phenomenon, a multiplication factor $f$ was introduced, which provides a zero particle convection term at velocities below $U_{\mathrm{mr}}$ and a smooth increase between $U_{\mathrm{mr}}$ and $U_{\mathrm{opt}}$

$$
\begin{gathered}
U<U_{\mathrm{mf}}: \quad f=0 \\
U_{\mathrm{mr}}<U<U_{\mathrm{opt}}: \quad f=\left(\frac{U-U_{\mathrm{mr}}}{U_{\mathrm{opt}}-U_{\mathrm{mr}}}\right)^{C}
\end{gathered}
$$

with $C$ being a constant, and

$$
U>U_{\text {opt }}: f=1 .
$$

A value of $C=0.3$ proved to give the best results. Factor $f$ is inserted in relation (2)

$$
N u=2.62 f A r^{0.1}(1-\varepsilon)^{2 / 3}+0.033 \operatorname{Re} \operatorname{Pr}(1-\varepsilon)^{2 / 3} / \varepsilon .
$$

From equations (1), (2) and (6) it is clear that the porosity is an important parameter in the heat transfer process. The simple relationships to predict porosity, originally advised in the model [2], are

$$
\begin{aligned}
& \varepsilon=1-\left(1-\varepsilon_{\mathrm{m} r}\right) /\left(1+0.7\left(H_{\mathrm{mr}} / d_{\mathrm{B}}\right)^{1 / 2} F^{1 / 3}\right) \\
& \varepsilon=\varepsilon_{\mathrm{mr}}+1.56\left(\operatorname{Re}-\operatorname{Re}_{\mathrm{mr}}\right)\left(1-\varepsilon_{\mathrm{mr}}\right) / A r^{1 / 2}
\end{aligned}
$$

This porosity model yields results which are too high at velocities beyond $U_{\text {opt }}$. A better model was recently described by Glicksman et al. [3]. It is based on a firstprinciples theory of gas flow. The model consists of five equations for use with different geometries, with and without pipes in the bed. We used the equations without pipes. These equations have to be solved simultaneously

$$
\begin{gathered}
K=\exp \left[\delta\left(1.4+\frac{7.6}{H / d_{\mathrm{b}}}\right)\right]_{=\prime \prime} \\
U=K U_{\mathrm{mr}}+\delta\left(U-U_{\mathrm{mr}}+0.71 \sqrt{ }\left(g d_{\mathrm{b}}\right)\right) \\
d_{\mathrm{bo}}=\max \left\{\left[\frac{1.3}{\left.g^{0.2}\left(\frac{U-K U_{\mathrm{mr}}}{N_{0}}\right)^{0.4}\right],}\right.\right. \\
\left.\left[3.69 \frac{\left(U-K U_{\mathrm{mr}}\right)^{2}}{g}\right]\right\}
\end{gathered}
$$

$d_{\mathrm{b}}=$

$$
\begin{gathered}
{\left[\left(d_{\mathrm{bo}}\right)^{10 / 7}+\frac{2.6 z\left(U / U_{\mathrm{mr}}-K\right)\left(U-U_{\mathrm{mr}}\right)^{6 / 7}}{\left(U / U_{\mathrm{mr}}-1\right) g^{3 / 7}}\right]^{7 / 10}} \\
H=H_{\mathrm{mr}} /(1-\delta) .
\end{gathered}
$$

For other configurations we refer to ref. [3].

\section{EXPERIMENTS}

The experiments were executed in a cold fluidized bed, the internal diameter of which was $290 \mathrm{~mm}$. With all experiments, the bed height at minimum fluidization was $300 \mathrm{~mm}$. The bed was made of Plexiglas, and was mounted on a steel windbox. The distributor consisted of two perforated metal sheets and a felt 


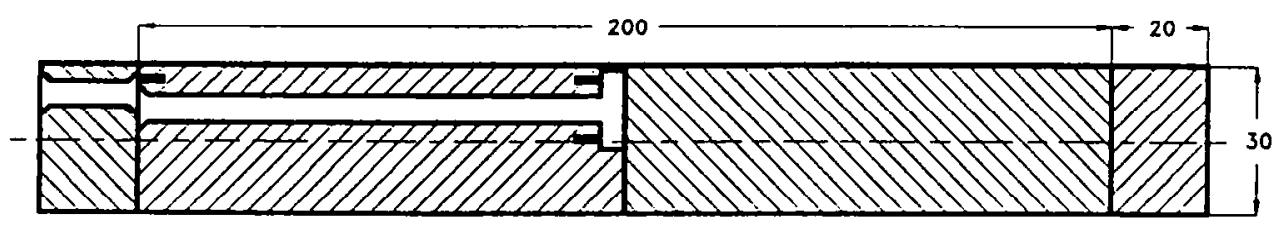

FIG. 1. Heat transfer probe.

cloth pressed in between, necessary to obtain a sufficient pressure drop over the distributor. Pressure transducers which could be inserted in the bed up to $150 \mathrm{~mm}$ from the wall, were mounted at distances of $50,150,250$ and $350 \mathrm{~mm}$ above the distributor. The fluidizing air was supplied by a centrifugal blower, the maximum fluidizing velocity that could be obtained was $1.5 \mathrm{~m} \mathrm{~s}^{-1}$. The mass flow of this air was measured. To measure the heat transfer coefficient from an immersed surface to the fluidized bed, we used a copper cylinder (Fig. 1), length 200 and diameter $30 \mathrm{~mm}$. Both ends were insulated with Teflon cylinders, length $20 \mathrm{~mm}$. Two copper-constantan thermocouples were used to measure the cylinder temperature. The cylinder was heated in an oven before being inserted in the bed. A temperature-time curve was registered during the period when the temperature difference between the cylinder and the bed sank from 70 to $41^{\circ} \mathrm{C}$. The mean bed temperature was $35^{\circ} \mathrm{C}$. For calculating $\mathrm{Nu}$, a heat balance was used. We determined bed porosity by measuring pressure differences between probes at different heights in the bed. These differences are related to porosity by $\Delta p / \Delta p_{\mathrm{mr}}=$ $(1-\varepsilon) /\left(1-\varepsilon_{\mathrm{n}, \mathrm{r}}\right)[4]$.

\section{Sand sizes}

The five samples of sand that were tested, had mean particle diameters of $0.43,0.61,0.86,1.20$, and 1.55 $\mathrm{mm}$, respectively, and a narrow particle size distribution. Mixture 1 consisted of samples 1 and 3, in relative amounts so that the mean particle diameter according to

$$
d_{\mathrm{p}}=1 / \Sigma\left(w_{i} / d_{\mathrm{p} i}\right)
$$

was $0.61 \mathrm{~mm}$. In the same way mixture 2 consisted of samples 3 and 5 , and had a mean particle diameter of $1.20 \mathrm{~mm}$.

\section{RESULTS AND DISCUSSION}

For all sand samples and mixtures, we measured the porosity and heat transfer coefficient as a function of fluidizing velocity, which ranged from $U_{\mathrm{mr}}$ to $1.5 \mathrm{~m}$ $\mathrm{s}^{-1}$ in steps of approximately $0.1 \mathrm{~m} \mathrm{~s}^{-1}$.

The experimental values of porosity were compared with the values calculated with relations (7) and (8) (Fig. 2). The standard deviation over all values, of the experimental relative to the calculated values is 0.046 . The same experimental values are compared to the results of the calculations performed with the porosity model represented by equations (9)-(13) (Fig. 3).

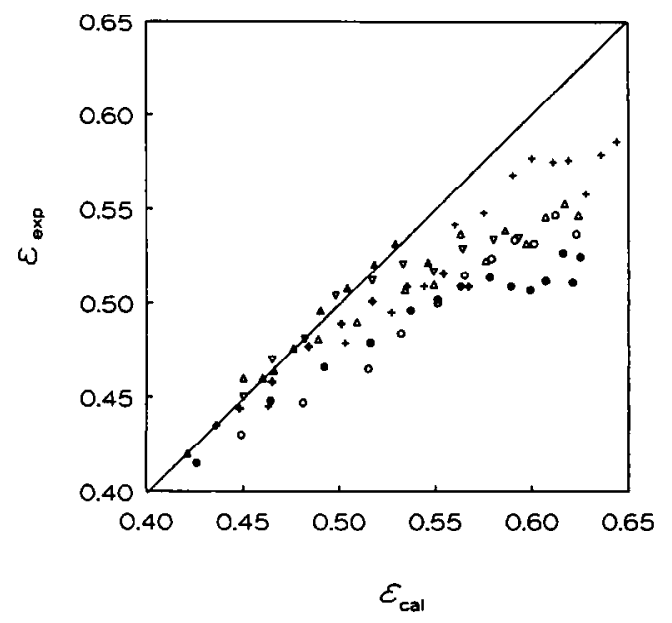

FIG. 2. Comparison between experimental results (samples I -5 and mixtures 1,2$)$ and model calculations [equations (7) and (8)]: + , sample $1 ; \triangle$, sample $2 ; 0$, sample $3 ;+$, sample $4 ; \boldsymbol{\Delta}$, sample $5 ; \boldsymbol{\ominus}$, mixture $1 ; \nabla$, mixture 2 .

Herc the standard deviation is 0.013 . It is clear that the Glicksman model is to be preferred here.

In the same way, our heat transfer measurements are presented in Figs. 4 and 5. In Fig. 4 the measured Nusselt numbers are presented, compared with the Nusselt numbers calculated with relation (2) with the use of equations (7) and (8). Calculated values seem to

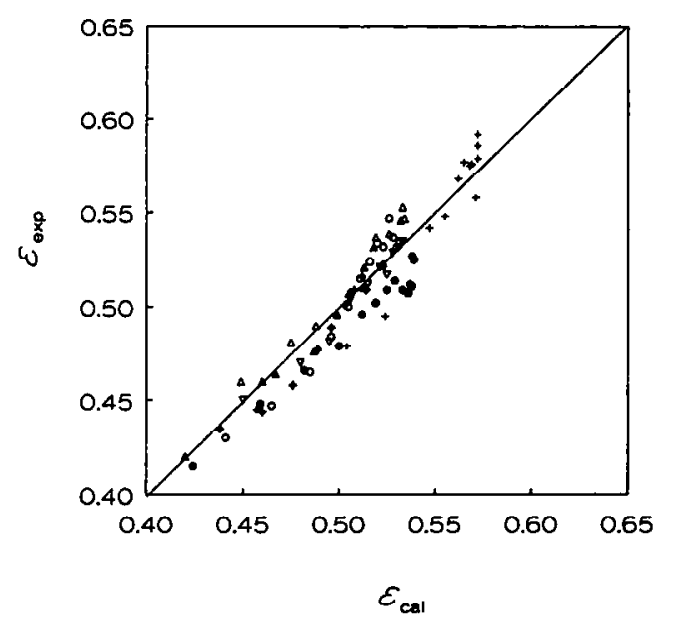

FIG. 3. Comparison between experimental results (samples $1-5$ and mixtures 1,2$)$ and model calculations [equations (9)-(I3)] : + , sample $1 ; \Delta$, sample $2 ; O$, sample $3 ;+$, sample $4 ; \Delta$, sample $5 ; \bullet$, mixture $1 ; \nabla$, mixture 2 . 


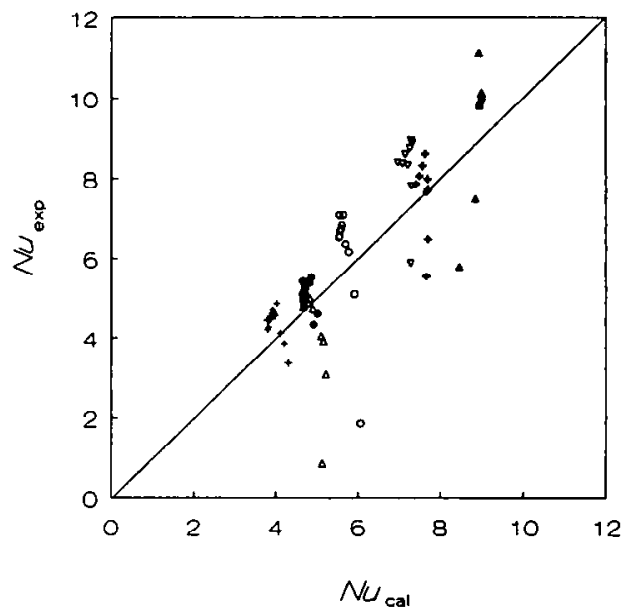

FIG. 4. Comparison between experimental results (samples $1-5$ and mixtures $(, 2)$ and model calculations [equation (2), using equations (7) and (8)] + , sample $1: \triangle$, sample $2 ; 0$, sample $3 ;+$, sample $4 ; \boldsymbol{\Delta}$, sample $5 ; \boldsymbol{Q}$, mixture $1 ; \nabla$, mixture 2

be almost constant : hardly any influence of fluidizing velocity on heat transfer is shown. The standard deviation is 1.19. In Fig. 5 measurements are shown, compared to equation (6) using (9)-(13). Measurements vary along the line $N u_{\text {cal }}=N u_{\text {exp }}$ which shows the influence of velocity. Here the standard deviation is 1.08 .

Conclusions from these results are that the porosity model developed by Glicksman et al. [3] gives closer predictions than the porosity equations advised by Borodulya et al. [2] and that the use of this model, together with the modification for low velocities advised here, improves accuracy of the prediction of

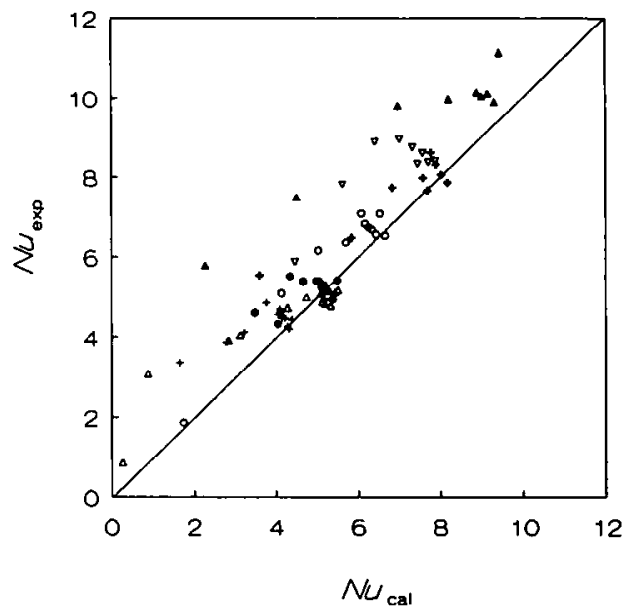

FIG. 5. Comparison between experimental results (samples 1-5 and mixtures 1,2 ) and model calculations [equation (6), using equations $(9)-(13)]:+$, sample $1 ; \Delta$, sample $2 ; 0$, sample $3 ;+$, sample $4 ; \Delta$, sample $5 ; \boldsymbol{O}$, mixture $1 ; \nabla$, mixture 2 . the heat transfer coefficient by Borodulya's model. The heat transfer coefficient of sand with a wide particle size distribution can also be calculated with the model, using equation (14). We emphasize that the fluidized bed we used in our experiments was of different magnitude than those used by Borodulya $e t$ al. [2] and Glicksman et al. [3] and recognize that deviation from our results is possible in different sized beds.

\section{REFERENCES}

I. V. A. Borodulya, Yu. S. Teplitsky, I. I. Markevich A. F. Hassan and T. P. Yeryomenko, Heat transfer between a surface and a fluidized bed: consideration of pressure and temperature effects, Int. J. Heat Mass Transfer 34, 47-53 (1991).

2. V. A. Borodulya, V. L. Ganzha, Yu. S. Teplitsky and Yu. G. Epanov, Heat transfer in fluidized beds, J. Engng Phys. 49(4), 621-626(1985).

3. L. R. Glicksman, T. Yule and A. Dyrness, Prediction of the expansion of fuidized beds containing lubes, Chem. Engng Sci. 46, 1561-1571 (1991).

4. A. I. Tamarin and Yu. S. Teplitsky, Expansion of an inhomogeneous fluidized bed, J. Engng Phys. 32(3), 469473 (1977).

\section{APPENDIX}

Table Al. Porosity measurements

\begin{tabular}{cccc}
\hline Velocity & $\begin{array}{c}\text { Experimental } \\
\text { value }\end{array}$ & Borodulya & Glicksman \\
\hline Fraction 1 & & & \\
0.155 & 0.445 & 0.463 & 0.457 \\
0.273 & 0.479 & 0.503 & 0.504 \\
0.364 & 0.495 & 0.527 & 0.524 \\
0.449 & 0.509 & 0.544 & 0.537 \\
0.537 & 0.542 & 0.560 & 0.547 \\
0.635 & 0.548 & 0.575 & 0.555 \\
0.757 & 0.568 & 0.590 & 0.562 \\
0.848 & 0.577 & 0.600 & 0.565 \\
0.945 & 0.575 & 0.611 & 0.568 \\
1.035 & 0.576 & 0.619 & 0.569 \\
1.135 & 0.558 & 0.628 & 0.571 \\
1.238 & 0.579 & 0.636 & 0.572 \\
1.349 & 0.586 & 0.644 & 0.572 \\
1.488 & 0.592 & 0.653 & 0.572 \\
Fraction 2 & & & \\
0.243 & 0.420 & 0.421 & 0.420 \\
0.352 & 0.460 & 0.450 & 0.449 \\
0.446 & 0.481 & 0.489 & 0.475 \\
0.523 & 0.490 & 0.509 & 0.488 \\
0.647 & 0.507 & 0.534 & 0.505 \\
0.742 & 0.510 & 0.549 & 0.513 \\
0.839 & 0.537 & 0.563 & 0.519 \\
0.933 & 0.523 & 0.576 & 0.523 \\
1.028 & 0.539 & 0.586 & 0.526 \\
1.129 & 0.532 & 0.597 & 0.529 \\
1.235 & 0.546 & 0.607 & 0.532 \\
1.346 & 0.553 & 0.617 & 0.533 \\
1.430 & 0.547 & 0.624 & 0.534
\end{tabular}


Table Al_-C Continued

\begin{tabular}{|c|c|c|c|}
\hline Velocity & $\begin{array}{l}\text { Experimental } \\
\text { value }\end{array}$ & Borodulya & Glicksman \\
\hline \multicolumn{4}{|l|}{ Fraction 3} \\
\hline 0.459 & 0.430 & 0.449 & 0.441 \\
\hline 0.550 & 0.447 & 0.481 & 0.465 \\
\hline 0.658 & 0.465 & 0.515 & 0.485 \\
\hline 0.747 & 0.484 & 0.532 & 0.496 \\
\hline 0.857 & 0.500 & 0.551 & 0.505 \\
\hline 0.953 & 0.515 & 0.565 & 0.511 \\
\hline 1.056 & 0.524 & 0.579 & 0.516 \\
\hline 1.162 & 0.534 & 0.591 & 0.520 \\
\hline 1.256 & 0.532 & 0.601 & 0.523 \\
\hline 1.374 & 0.547 & 0.612 & 0.526 \\
\hline 1.508 & 0.537 & 0.623 & 0.528 \\
\hline \multicolumn{4}{|l|}{ Fraction 4} \\
\hline 0.675 & 0.435 & 0.436 & 0.438 \\
\hline 0.769 & 0.444 & 0.448 & 0.460 \\
\hline $0.87 !$ & 0.458 & 0.465 & 0.476 \\
\hline 0.984 & 0.477 & 0.484 & 0.489 \\
\hline 1.081 & 0.489 & 0.501 & 0.496 \\
\hline 1.178 & 0.501 & 0.517 & 0.503 \\
\hline 1.280 & 0.509 & 0.535 & 0.508 \\
\hline 1.393 & 0.516 & 0.554 & 0.512 \\
\hline 1.472 & 0.509 & 0.567 & 0.514 \\
\hline \multicolumn{4}{|l|}{ Fraction 5} \\
\hline 0.817 & 0.460 & 0.460 & 0.460 \\
\hline 0.913 & 0.464 & 0.466 & 0.467 \\
\hline 1.006 & 0.476 & 0.476 & 0.487 \\
\hline 1.108 & 0.496 & 0.490 & 0.499 \\
\hline 1.197 & 0.508 & 0.504 & 0.506 \\
\hline 1.303 & 0.521 & 0.518 & 0.513 \\
\hline 1.382 & 0.532 & 0.529 & 0.518 \\
\hline 1.505 & 0.522 & 0.546 & 0.522 \\
\hline \multicolumn{4}{|l|}{ Mixture 1} \\
\hline 0.224 & 0.415 & 0.426 & 0.424 \\
\hline 0.306 & 0.448 & 0.464 & 0.459 \\
\hline 0.398 & 0.466 & 0.492 & 0.482 \\
\hline 0.502 & 0.479 & 0.516 & 0.500 \\
\hline 0.612 & 0.496 & 0.537 & 0.512 \\
\hline 0.701 & 0.502 & 0.551 & 0.519 \\
\hline 0.795 & 0.509 & 0.563 & 0.525 \\
\hline 0.905 & 0.514 & 0.578 & 0.529 \\
\hline 1.010 & 0.509 & 0.589 & 0.533 \\
\hline 1.108 & 0.507 & 0.599 & 0.536 \\
\hline 1.200 & 0.512 & 0.607 & 0.537 \\
\hline 1.315 & 0.527 & 0.616 & 0.538 \\
\hline 1.382 & $0.5 \mathrm{II}$ & 0.621 & 0.538 \\
\hline 1.431 & 0.525 & 0.625 & 0.539 \\
\hline \multicolumn{4}{|l|}{ Mixture 2} \\
\hline 0.600 & 0.450 & 0.450 & 0.450 \\
\hline 0.696 & 0.470 & 0.465 & 0.480 \\
\hline 0.795 & 0.481 & 0.482 & 0.495 \\
\hline 0.896 & 0.504 & 0.498 & 0.506 \\
\hline 1.006 & 0.512 & 0.517 & 0.515 \\
\hline 1.108 & 0.521 & 0.533 & 0.521 \\
\hline 1.200 & 0.517 & 0.549 & 0.525 \\
\hline 1.292 & 0.529 & 0.564 & 0.528 \\
\hline 1.388 & 0.534 & 0.580 & 0.531 \\
\hline 1.470 & 0.535 & 0.593 & 0.533 \\
\hline
\end{tabular}

Table A2. Heat transfer measurements

\begin{tabular}{|c|c|c|c|}
\hline Velocity & $\begin{array}{l}\text { Experimental } \\
\text { value }\end{array}$ & Borodulya & Glicksman \\
\hline \multicolumn{4}{|l|}{ Fraction 1} \\
\hline 0.169 & 3.36 & 4.30 & 1.65 \\
\hline 0.254 & 3.86 & 4.20 & 2.78 \\
\hline 0.329 & 4.12 & 4.11 & 3.22 \\
\hline 0.472 & 4.86 & 4.02 & 3.77 \\
\hline 0.563 & 4.57 & 3.98 & 4.05 \\
\hline 0.624 & 4.63 & 3.95 & 4.08 \\
\hline 0.707 & 4.70 & 3.92 & 4.09 \\
\hline 0.785 & 4.62 & 3.90 & 4.11 \\
\hline 0.848 & 4.47 & 3.88 & 4.14 \\
\hline 0.937 & 4.55 & 3.86 & 4.17 \\
\hline 1.049 & 4.47 & 3.84 & 4.22 \\
\hline 1.175 & 4.27 & 3.82 & 4.28 \\
\hline 1.256 & 4.20 & 3.80 & 4.32 \\
\hline 1.355 & 4.44 & 3.79 & 4.38 \\
\hline \multicolumn{4}{|l|}{ Fraction 2} \\
\hline 0.189 & 0.85 & 5.13 & 0.26 \\
\hline 0.268 & 3.08 & 5.22 & 0.88 \\
\hline 0.340 & 3.92 & 5.16 & 2.84 \\
\hline 0.360 & 4.05 & 5.10 & 3.12 \\
\hline 0.495 & 4.73 & 4.90 & 4.28 \\
\hline 0.600 & 4.99 & 4.83 & 4.74 \\
\hline 0.707 & 4.88 & 4.78 & 5.13 \\
\hline 0.799 & 5.10 & 4.75 & 5.10 \\
\hline 0.905 & 4.96 & 4.71 & 5.15 \\
\hline 0.980 & 4.83 & 4.70 & 5.20 \\
\hline 1.095 & 4.88 & 4.68 & 5.27 \\
\hline 1.181 & 4.78 & 4.66 & 5.34 \\
\hline 1.231 & 5.03 & 4.66 & 5.37 \\
\hline 1.315 & 5.12 & 4.65 & 5.44 \\
\hline 1.399 & 5.17 & 4.64 & 5.51 \\
\hline \multicolumn{4}{|l|}{ Fraction 3} \\
\hline 0.433 & 1.86 & 6.06 & 1.74 \\
\hline 0.537 & 5.09 & 5.91 & 4.13 \\
\hline 0.635 & 6.16 & 5.77 & 5.03 \\
\hline 0.747 & 6.36 & 5.69 & 5.70 \\
\hline 0.852 & 7.08 & 5.63 & 6.08 \\
\hline 0.945 & 6.83 & 5.60 & 6.17 \\
\hline 1.035 & 6.74 & 5.58 & 6.25 \\
\hline 1.129 & 6.69 & 5.56 & 6.33 \\
\hline 1.238 & 6.56 & 5.55 & 6.44 \\
\hline 1.326 & 7.08 & 5.54 & 6.53 \\
\hline 1.447 & 6.53 & 5.53 & 6.66 \\
\hline \multicolumn{4}{|l|}{ Fraction 4} \\
\hline 0.690 & 5.54 & 7.65 & 3.59 \\
\hline 0.785 & 6.48 & 7.69 & 5.84 \\
\hline 0.880 & 7.73 & 7.69 & 6.83 \\
\hline 0.984 & 7.98 & 7.68 & 7.58 \\
\hline 1.046 & 7.66 & 7.66 & 7.68 \\
\hline 1.138 & 8.61 & 7.62 & 7.77 \\
\hline 1.231 & 8.31 & 7.56 & 7.89 \\
\hline 1.335 & 8.06 & 7.48 & 8.02 \\
\hline 1.436 & 7.86 & 7.40 & 8.17 \\
\hline \multicolumn{4}{|l|}{ Fraction 5} \\
\hline 0.747 & 5.79 & 8.45 & 2.27 \\
\hline 0.880 & 7.49 & 8.84 & 4.50 \\
\hline 0.965 & 9.81 & 8.93 & 6.97 \\
\hline 1.056 & 9.98 & 8.97 & 8.20 \\
\hline 1.158 & 10.15 & 8.99 & 8.89 \\
\hline 1.250 & 10.05 & 8.99 & 9.00 \\
\hline 1.349 & 10.12 & 8.97 & 9.15 \\
\hline 1.447 & 9.91 & 8.94 & 9.31 \\
\hline 1.570 & 11.13 & 8.92 & 9.43 \\
\hline
\end{tabular}


Table A2.-Continued

\begin{tabular}{rccc}
\hline Velocity & $\begin{array}{c}\text { Experimental } \\
\text { value }\end{array}$ & Borodulya & Glicksman \\
\hline Mixture 1 & & & \\
0.350 & 4.61 & 5.01 & 3.48 \\
0.433 & 4.33 & 4.92 & 4.04 \\
0.509 & 5.52 & 4.86 & 4.34 \\
0.594 & 5.39 & 4.82 & 4.66 \\
0.727 & 5.40 & 4.76 & 4.99 \\
0.813 & 5.40 & 4.74 & 5.05 \\
0.909 & 5.24 & 4.71 & 5.11 \\
1.002 & 5.30 & 4.70 & 5.17 \\
1.115 & 5.14 & 4.68 & 5.25 \\
1.191 & 5.15 & 4.67 & 5.27 \\
1.292 & 4.94 & 4.66 & 5.39 \\
1.404 & 5.42 & 4.65 & 5.49 \\
& & & \\
Mixture 2 & & & \\
0.647 & 5.88 & 7.27 & 4.46 \\
0.737 & 7.81 & 7.29 & 5.62 \\
0.839 & 8.88 & 7.30 & 6.41 \\
0.941 & 8.95 & 7.28 & 7.01 \\
1.035 & 8.75 & 7.25 & 7.32 \\
1.149 & 8.33 & 7.20 & 7.45 \\
1.244 & 8.60 & 7.14 & 7.57 \\
1.343 & 8.37 & 7.07 & 7.71 \\
1.460 & 8.40 & 6.96 & 7.88 \\
\hline & & & \\
\hline
\end{tabular}

